\title{
Haemophilus influenzae tipo b: situação epidemiológica no Estado de Minas Gerais, Brasil, 1993 a 1997
}

\author{
Haemophilus influenzae type b: \\ epidemiological situation in the State \\ of Minas Gerais, Brazil, 1993-1997
}

Sybelle de Souza Castro Miranzi 1

Luiz Antonio Bastos Camacho 2

Joaquim Gonçalves Valente 2

1 Centro de Graduação em Enfermagem, Faculdade de Medicina do Triângulo Mineiro. Praça Manoel Terra 330, Uberaba, $M G$ 38015-050, Brasil. sybelle@mednet.com.br 2 Departamento de Epidemiologia e Métodos Quantitativos em Saúde Escola Nacional de Saúde Pública, Fundação Oswaldo Cruz. Rua Leopoldo Bulhões 1480, Rio de Janeiro, $R J$ 21041-210, Brasil.

luiz.camacho@ensp.fiocruz.br jval9999@gbl.com.br
Abstract Among Haemophilus influenzae type b (Hib) invasive diseases, pneumonia and meningitis are the most relevant in public health due to their frequency and severity. From 1993 to 1997, there were 720 cases of Hib meningitis in Minas Gerais State, Brazil, representing the most frequent cause of bacterial meningitis in infants $(<1$ year) and the second most frequent among all causes of meningitis. The total estimated cases of invasive Hib diseases thus appear to justify the recent inclusion of the vaccine in the basic immunization protocol. The vaccine's high cost reinforces the need for more precise monitoring of the etiological diagnosis of meningitis cases, representing one of the weaknesses in the prevailing epidemiological surveillance system. Key words Meningitis; Pneumonia; Haemophilus Infections; Haemophilus influenzae Type B

Resumo Entre as doenças invasivas causadas pelo Haemophilus influenzae tipo b (Hib), destacam-se, pela freqüência e gravidade, as pneumonias e as meningites. No período de 1993 a 1997, foram notificados, em Minas Gerais, 720 casos de meningites por Hib, sendo a causa mais freqüente de meningite bacteriana em menores de um ano e a segunda causa no total de meningites. Entretanto, estimou-se uma ocorrência total de 1.160 casos considerando as meningites bacterianas não especificadas. O total de casos estimados de doença invasiva por Hib parece justificar a recente inclusão da vacina no esquema básico de imunizações. O alto custo da vacina reforça a necessidade de melhorar a vigilância epidemiológica da meningite, que constitui uma das fragilidades das ações de controle desta doença.

Palavras-chave Meningite; Pneumonia; Infecções por Haemophilus; Haemophilus influenzae Tipo B 


\section{Introdução}

Os Haemophilus influenzae (Hi) encapsulados são responsáveis por doenças invasivas como: meningite, epiglotite, pneumonia, artrite séptica, abcessos, pericardite, empiema, osteomielite e celulite. O sorotipo b é responsável por $95 \%$ das doenças invasivas causadas por $\mathrm{Hi}$ (Makela et al., 1992; WHO, 1996). Antes da vacinação, o Haemophilus influenzae tipo b (Hib) era o principal agente etiológico de meningite em países industrializados, causando entre $20 \%$ e $60 \%$ das meningites bacterianas (Funkhouser et al., 1991).

O Hib causa infecção em qualquer faixa etária, todavia é um microrganismo importante em patologia pediátrica, pela sua freqüência e gravidade na faixa etária de três meses a três anos. Em crianças menores de um ano de idade, o Hib é a causa mais freqüente de meningite bacteriana em todo o mundo (Levine et al., 1998; Ward \& Zangwill, 1999).

A doença invasiva por Hib ocorre em pequena fração de pessoas infectadas, e a transmissão se dá pelas vias respiratórias. O microrganismo pode permanecer na nasofaringe por meses, caracterizando o estado de portador são (CDC, 1998; Levine et al., 1998; MS, 1999; Ward \& Zangwill, 1999).

O quadro clínico não permite distinguir a meningite por Hib de outras meningites bacterianas. O diagnóstico etiológico depende de métodos laboratoriais, como cultura de líquor, teste de aglutinação do látex e contra-imunoeletroforese.

Os fatores de risco incluem atendimento em creches, número de crianças no domicílio, aglomeração intradomiciliar, baixo poder aquisitivo, asplenia ou esplenectomia, anemia falciforme, ou síndromes de deficiência de anticorpos, além dos fatores que modificam a suscetibilidade, por exemplo, tempo de amamentação materna (Takala \& Clements, 1992; WHO, 1996).

Em todo o mundo, o Hib causa meningite bacteriana e infecções respiratórias agudas e resultava, antes da utilização da vacina, em, pelo menos, três milhões de casos de sérias doenças e 400 mil mortes a cada ano em crianças menores de cinco anos de idade (WHO, 1997).

A incidência de meningite por Hib em menores de cinco anos de idade, nos Estados Unidos, antes da introdução da vacina, foi estimada em 50-65 casos por 100 mil habitantes, correspondendo a $44 \%$ dos casos de meningite. $\mathrm{Na}$ Índia, a estimativa da incidência foi de 39 casos e em refugiados vietnamitas de 43 casos por 100 mil habitantes (Salisbury, 1998). Na Eu- ropa, a incidência varia de 20 a 60 por $100 \mathrm{mil}$ habitantes.

No Brasil, entre 1983 e 1996, foram notificados 15.927 casos de meningite por Hib representando aproximadamente $5 \%$ do total de meningites notificadas, dos quais 7.607 (47,8\%) em menores de um ano e $14.243(89,4 \%)$ em menores de cinco anos (MS, 1999).

Nos anos de 1990 a 1995, a taxa de incidência de meningite por Hib no Brasil oscilou entre 14,4 e 23,4 por 100 mil habitantes em menores de um ano, e 2,9 a 4,8 em crianças de um a quatro anos. Estas taxas podem ter sido subestimadas, considerando que, de 1987 a 1996, as meningites sem especificação de etiologia corresponderam a um terço das meningites notificadas e que vários Estados brasileiros não enviaram dados.

A taxa de mortalidade por meningite causada por Hib variava entre dois a oito por 100 mil nos Estados Unidos antes da introdução da vacina conjugada nos programas de vacinação (Howard, 1992). A letalidade continua elevada, variando de $11 \%$ a $35 \%$ em menores de um ano de idade. O prognóstico das meningites depende da precocidade com que o diagnóstico é feito, da identificação do agente etiológico, da idade e das condições clínicas do paciente, além do início imediato do tratamento.

As vacinas conjugadas fazem parte da rotina de imunização infantil de muitos países. Em alguns deles, onde os dados de ocorrência da doença têm sido coletados, a taxa de incidência diminuiu em $90 \%$ após um a quatro anos de introdução da vacina na rotina de imunização. A capacidade da vacina em reduzir a freqüência de portadores da bactéria na faringe parece potencializar a imunidade de grupo em populações imunizadas (Mulholland et al., 1997).

No Brasil, a vacina foi introduzida na rotina do Programa Nacional de Imunizações (PNI) em meados de 1999, para crianças de dois a 23 meses (MS, 1999). É uma vacina relativamente cara (US\$ 4 a US\$ 7) comparada com as outras vacinas do programa básico de imunizações (WHO, 1997). Alguns autores, como Hussey et al. (1995) e Battaglin et al. (1998), têm demonstrado que os benefícios alcançados superam os custos com a implantação da vacina na rotina de imunização infantil.

Com a recente introdução da vacina contra Hib no calendário do PNI, e as limitações dos dados sobre a doença no Brasil, julgamos oportuno analisar os dados de notificação de meningites do Estado de Minas Gerais de modo a traçar um perfil epidemiológico da doença. Minas Gerais, pela sua grande extensão territorial, grande população e diversidade de ce- 
nários administrativos e graus de desenvolvimento econômico, permite múltiplas possibilidades de análise da situação epidemiológica da meningite por Hib e suas implicações para o programa de imunizações.

\section{Material e métodos}

O estudo se baseou na análise do banco de dados informatizado, com os casos notificados e confirmados de meningites de janeiro de 1993 a dezembro de 1997, fornecido pela Secretaria Estadual da Saúde de Minas Gerais. Esse banco de dados foi construído com base em Fichas Individuais de Investigação de Meningites, relativas ao período. Foram estudados 11.441 casos confirmados de meningite, sendo 720 causadas por Hib.

As variáveis utilizadas foram: etiologia ou grupo etiológico, ano de ocorrência, faixa etária, mês de ocorrência, nome do município de procedência, zona de procedência urbana ou rural, etiologia da meningite, critério diagnóstico utilizado, data do óbito, se houver, região de ocorrência (Município de Belo Horizonte, região metropolitana ou interior do Estado) e Diretoria Regional de Saúde (DRS) de ocorrência do caso.

Estimou-se, considerando-se a proporção de notificações de meningites por Hib entre as meningites bacterianas especificadas, um número aproximado de meningites por Hib entre as meningites bacterianas não especificadas $\mathrm{e}$, posteriormente, estratificou-se por faixa etária.

Para o cálculo de taxas, foram criados arquivos com dados agregados, de acordo com a área de estudo, faixa etária, etiologia e grandes grupos de agentes etiológicos. As idades foram agregadas por faixa etária, divididas em menores de um ano $(<1)$, de um a quatro anos (1-4) e a faixa etária de cinco anos e mais $(5 \mathrm{e}+)$. Para o cálculo das taxas e da letalidade, elaboração de gráficos e análise dos dados, foram utilizados os seguintes programas: Excel (versão 7.0) e Epi Info (versão 6.04b).

Para comparação com Minas Gerais, foram selecionados outros Estados populosos com grande número de casos de meningite (Rio de Janeiro, São Paulo e Paraná), que disponibilizaram os dados,

A sazonalidade das meningites foi observada com base no número de casos de meningites, segundo meses e ano de ocorrência.

\section{Resultados}

No Estado de Minas Gerais, no período de 1993 a 1997 , foram notificados 11.441 casos de meningites, dos quais $5.649(49,4 \%)$ bacterianas, $3.111(27,2 \%)$ virais, $118(1,0 \%)$ por demais agentes etiológicos e 2.563 (22,4\%) não especificadas. Do total de meningites bacterianas, $62,0 \%$ tiveram a etiologia identificada e $38,0 \%$ foram classificadas como bacterianas não especificadas.

Os agentes etiológicos freqüentemente isolados foram Neisseria meningitidis (16,3\%), Haemophilus influenzae (6,3\%), Streptococcus pneumoniae $(5,4 \%)$ e Mycobacterium tuberculosis $(0,7 \%)$. As outras bactérias foram responsáveis por $1,8 \%$ do total de casos.

Dentre os 5.649 casos de meningites bacterianas, 38,0\% não tiveram os agentes etiológicos especificados. Os agentes etiológicos especificados mais freqüentes foram $N$. meningitidis com 1.868 (33,0\%) dos casos, H. influenzae com 720 (12,7\%) e S. pneumoniae com 621 $(11,0 \%)$.

A etiologia das meningites foi determinada por citoquímica em $44,6 \%$ dos casos, bacterioscopia em $11,7 \%$, cultura em 10,8\%, aglutinação do látex em 7,9\% e contra-imunoeletroforese em 1,8\%. Em 23,1\% dos casos, a classificação etiológica foi feita por critério clínico-epidemiológico. A meningite bacteriana especificada foi diagnosticada por cultura em $94,2 \%$ e aglutinação do látex em 3,8\% dos casos. A meningite bacteriana não especificada foi diagnosticada por citoquímica em $64,2 \%$, bacterioscopia em $34,9 \%$ e cultura em $0,3 \%$ dos casos.

Com relação à confirmação laboratorial dos 720 casos de meningites por Hib, 47,5\% foram confirmados por aglutinação do látex; 37,8\% por cultura, $13,6 \%$, por contra-imunoeletroforese, $1,0 \%$ por bacterioscopia e $0,1 \%$ foi caracterizado como meningite por Hib através do critério clínico-epidemiológico.

Dos 720 casos de meningite por Hib, 42,0\% ocorreram em menores de um ano de idade, sendo o maior número de casos entre os quatro e nove meses, e $45,3 \%$ em crianças de um a quatro anos de idade, totalizando $87,3 \% \mathrm{em}$ menores de cinco anos de idade e $12,0 \% \mathrm{em}$ indivíduos com cinco anos de idade ou mais. A concentração dos casos de meningite por Hib em menores de cinco anos de idade contrasta com os casos de meningites causadas por $N$. meningitidis e S. pneumoniae, que tiveram mais de 54,0\% de ocorrência em maiores de cinco anos de idade (Figura 1).

No período estudado, 20,5\% das meningites bacterianas especificadas foram causa- 
Figura 1

Distribuição proporcional das meningites bacterianas de maior ocorrência no Estado de Minas Gerais,

Brasil, no período de 1993 a 1997, segundo etiologia e faixa etária.

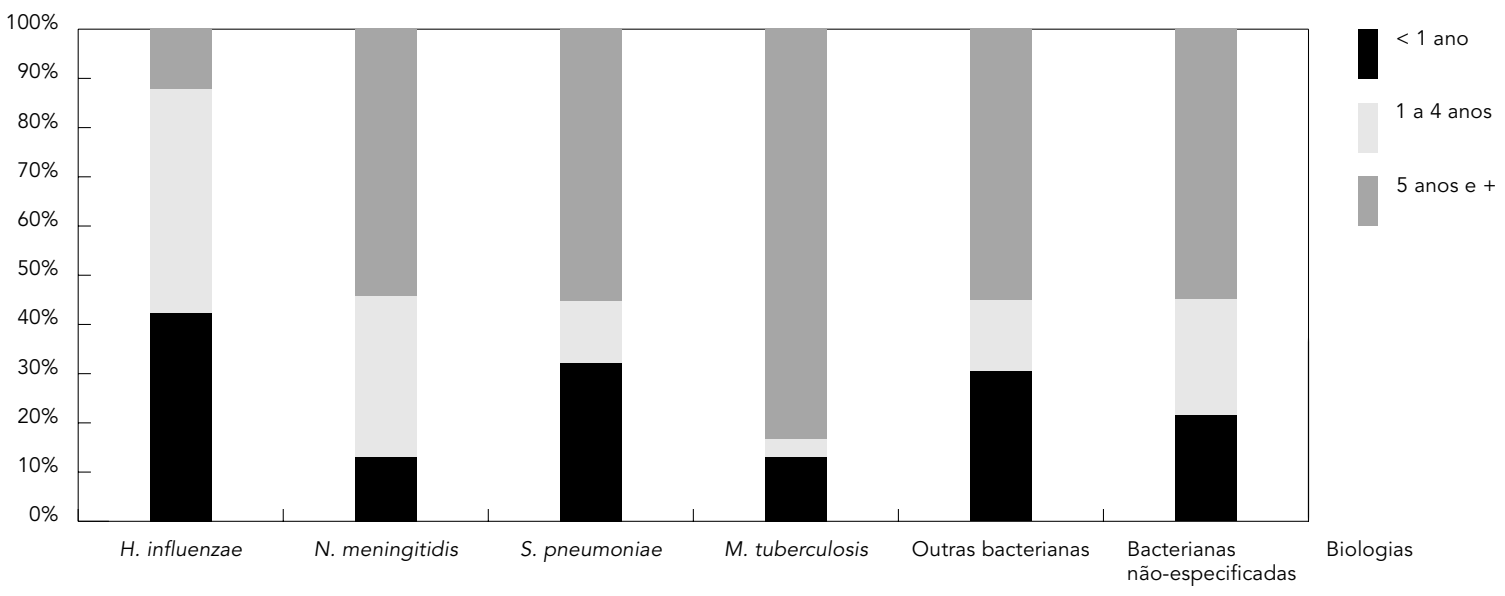

das por Hib. Em menores de um ano de idade e em menores de cinco anos, o Hib foi responsável por, respectivamente, $37,0 \%$ e $33,8 \%$ dos casos.

Com a porcentagem de casos de meningites por Hib contido nas meningites bacterianas especificadas (3.501), estimou-se a porcentagem de meningites por Hib que, provavelmente, estaria contida no total de meningites bacterianas não especificadas. De 2.148 casos de meningites bacterianas não especificadas, estimou-se que 441 casos seriam por Hib. Nesse caso, seriam 1.161 casos de meningite por Hib, ou seja, uma diferença de 441 casos a mais que poderiam ser devidos ao Hib e não tiveram a etiologia identificada. Essa diferença é de 170 casos em menores de um ano de idade e 326 casos em menores de cinco anos.

Comparado com São Paulo, Rio de Janeiro e Paraná, Minas Gerais foi o Estado que apresentou as menores taxas de incidência de meningite por Hib em menores de um ano de idade, em todos os anos da série. A taxa de incidência foi crescente no período de 1993 a 1996 nos Estados de Minas Gerais, Paraná e Rio de Janeiro (Figura 2).

Em Minas Gerais, a taxa de incidência de meningite por Hib, no período de 1993 a 1997, foi maior em menores de um ano, oscilando entre 9 para 24 por 100 mil habitantes.

A tendência da taxa de incidência em menores de um ano de idade foi semelhante em
Belo Horizonte, região metropolitana, interior e Estado de Minas Gerais como um todo. As taxas foram maiores em Belo Horizonte, seguida da região metropolitana e interior (Figura 3). O Município de Belo Horizonte e a região metropolitana concentraram $21,4 \%$ e $38,2 \%$, respectivamente, do total de casos de meningites por Hib do Estado de Minas Gerais.

No período estudado, dos óbitos de meningite por Hib considerando o local de residência, 18,0\% ocorreram em Belo Horizonte, $31,6 \%$ na região metropolitana e nos demais municípios do interior do Estado ocorreram 68,5\% dos óbitos.

A taxa de mortalidade de meningite por Hib oscilou de 1,3 a 8,0 por 100 mil habitantes entre as regiões. No Estado como um todo, a taxa de mortalidade foi maior em menores de um ano de idade, variou de 2 a 5 por 100 mil habitantes, seguida da faixa etária de um a quatro anos.

A letalidade foi maior no interior do Estado, seguido do Estado como um todo, região metropolitana e Belo Horizonte e oscilou de $6 \%$ a $30 \%$ entre as regiões (Tabela 1). No Estado, a letalidade foi maior em menores de um ano de idade e, comparada com a de outros Estados, como Rio de Janeiro, São Paulo e Paraná, foi maior em 1994 e 1997.

Em Minas Gerais, a análise da distribuição dos casos de meningite por Hib por mês de ocorrência revela que $61,0 \%$ das meningites por 
Taxa de incidência (por 100 mil habitantes) de meningite por Hib em menores de um ano de idade, em algumas Unidades da Federação e no Brasil, no período de 1993 a 1997.

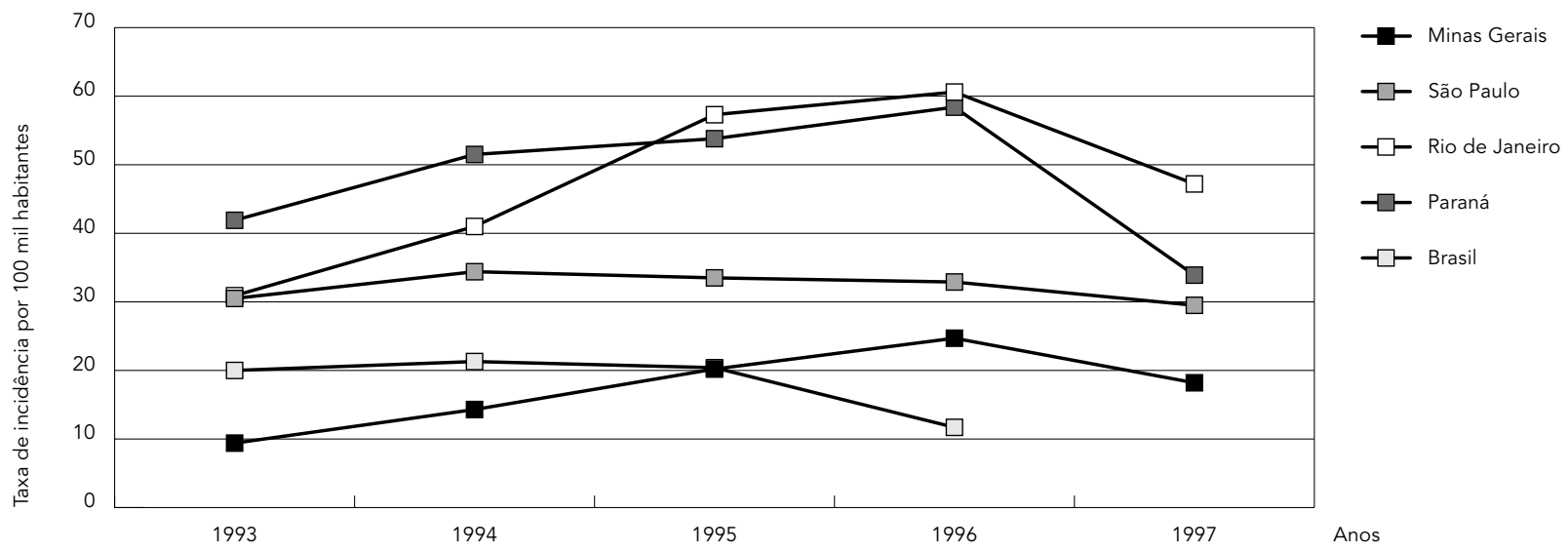

Figura 3

Taxa de incidência (por 100 mil habitantes) de meningite por Hib em menores de um ano de idade, em Belo Horizonte, região metropolitana, interior do Estado e Estado de Minas Gerais, no período de 1993 a 1997.

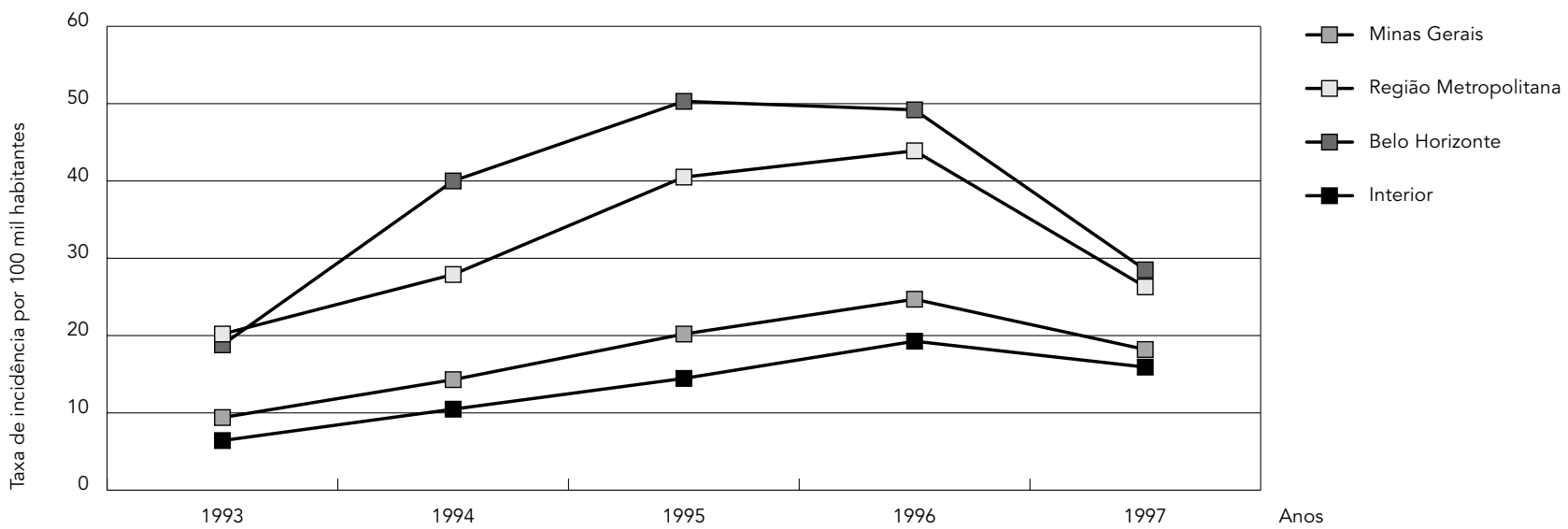


Tabela 1

Letalidade (\%) de meningite por Hib, em menores de um ano de idade, em Minas Gerais, no interior do Estado, região metropolitana e Belo Horizonte, no período de 1993 a 1997.

\begin{tabular}{lcccc}
\hline & Minas Gerais & Região metropolitana & Belo Horizonte & Interior \\
\hline 1993 & 21,9 & 6,7 & 14,3 & 35,29 \\
1994 & 30,6 & 28,6 & 20 & 32,14 \\
1995 & 11,4 & 9,7 & 15,8 & 12,82 \\
1996 & 14,9 & 8,8 & 10,5 & 18,86 \\
1997 & 27,7 & 28,6 & 18,2 & 27,27 \\
\hline
\end{tabular}

Hib ocorrem no outono e no inverno. Esse comportamento foi semelhante para todas as meningites bacterianas. Porém, observa-se o contrário com as meningites virais (Figura 4).

\section{Discussão}

De todas as doenças invasivas causadas por Hib, a meningite é a doença que apresenta melhor possibilidade de vigilância e controle, devido à obrigatoriedade da notificação e à hospitalização de quase todos os casos. Outras formas clínicas, como a pneumonia, não são de notificação compulsória e não têm exames laboratoriais realizados de rotina para identificação do agente etiológico. Nas meningites, a punção lombar e o exame do líquor são realizados em grande parte dos casos, mas a capacidade de identificar o agente etiológico é limitada pelos recursos de laboratório, pela coleta de espécimes após o início de antibioticoterapia, produzindo testes falso-negativos, entre outros. Além disso, uma parte dos casos em que se determina a etiologia se perde no sistema de informações.

A porcentagem de especificação do agente etiológico para as meningites é um dos indicadores para avaliar a qualidade do sistema de vigilância epidemiológica. Em Minas Gerais, no período de 1993 a 1997, 38,0\% das meningites bacterianas não tiveram o agente etiológico especificado, limitando a avaliação da conjuntura epidemiológica. Entretanto, para determinação do agente etiológico das meningites, verificamos que, entre as especificadas, na maioria foram realizados exames como cultura, aglutinação do látex e contra-imunoeletroforese, indicando a necessidade de se estipularem e padronizarem exames laboratoriais para as meningites como uma alternativa para melhora da qualidade das informações epidemiológicas dessa doença.
Para as doenças de notificação compulsória e que podem ser prevenidas por imunização, a padronização dos exames laboratoriais, ao menos na rede pública dos serviços de saúde, favoreceria o acompanhamento dos aspectos epidemiológicos das doenças, diagnósticos precoces e precisos, bem como um bom prognóstico, tornando possível o início imediato do tratamento e a prevenção de seqüelas e óbitos.

A mesma proporção de meningites por Hib contida nas meningites bacterianas_especificadas, aplicada nas meningites bacterianas não especificadas, resultou em 441 casos de meningites por Hib não identificados. Entretanto, essa estimativa não leva em consideração as subnotificações e a ineficiência dos exames laboratoriais, os quais levariam a um aumento no número de casos que deixaram de ser conhecidos como meningites bacterianas especificadas. Esse suposto aumento de casos poderá ser evidenciado na avaliação do impacto da vacinação contra o Hib.

A maior parte das meningites especificadas decorreram de $N$. meningitidis, $H$. influenzae ou S. pneumoniae. O Hib foi a segunda etiologia mais freqüente de meningites bacterianas especificadas, o que aponta a necessidade da implantação da vacina contra Hib no Estado de Minas Gerais, justificando-se pela prevenção de óbitos evitáveis e diminuição dos gastos com internações, tratamentos e seguimento das crianças que sobreviveram à meningite, para avaliação neurológica, psicomotora e sensorial.

A predominância do Hib na faixa etária dos menores de cinco anos de idade é compatível com a noção de que as crianças vão desenvolvendo resistência à doença como resultado de infecções subclínicas, inclusive por formas não capsuladas do Haemophilus e por outras bactérias.

A tendência crescente da taxa de incidência de meningite por Hib em menores de um ano 
Porcentagem de meningites por etiologias, segundo as estações do ano, no Estado de Minas Gerais, no período de 1993 a 1997.

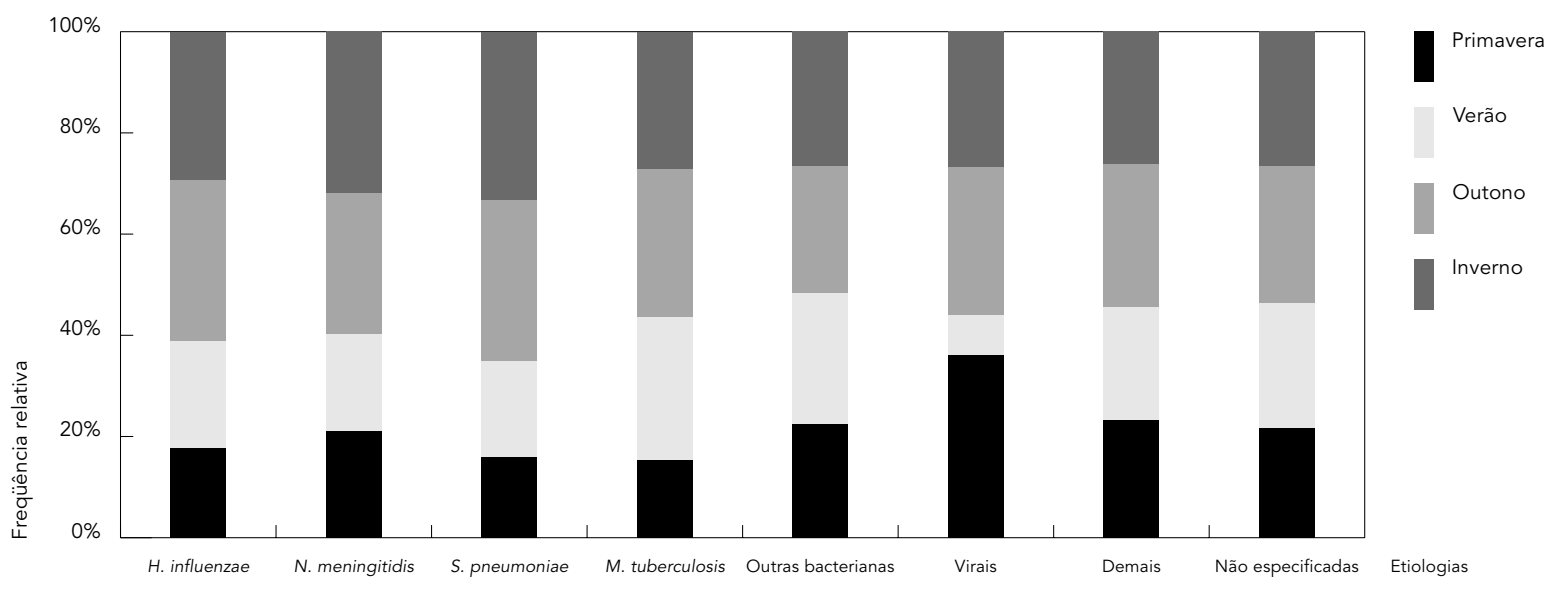

de idade, no período de 1993 a 1996, nos Estados de Minas Gerais, Paraná e Rio de Janeiro, ao contrário do que ocorreu no Brasil como um todo, não tem uma explicação epidemiológica plausível, sendo mais provável que se trate de um artefato do sistema de informação. Analogamente, problemas na vigilância epidemiológica em Minas Gerais poderiam estar justificando a menor freqüência da doença quando se compara com São Paulo, Rio de Janeiro e Paraná.

Belo Horizonte e demais municípios da região metropolitana notificaram maior número de casos (21,4\% e 38,2\% respectivamente), apesar de constituírem aproximadamente 25,0\% da população. Dois fatores podem explicar esta diferença: a urbanização que contribui para aumentar a ocorrência da doença, por facilitar os contatos inter-humanos que a propagam, e um sistema de notificação melhor estruturado, devido à proximidade da capital e, consequentemente, maiores possibilidades de acesso a treinamentos e capacitação de profissionais de saúde.

A letalidade pode ser afetada pela subnotificação diferenciada de casos e de óbitos. Ou seja, o sistema de vigilância epidemiológica tem chances diferenciadas para conhecer os casos que morrem e os que sobrevivem, pois, quando um caso vai a óbito, dificilmente são esperados os resultados dos exames laboratoriais para o preenchimento da Declaração de Óbito.
Isso aumenta as possibilidades de se preencher nos formulários como meningites bacterianas não especificadas. As chances de o sistema de vigilância identificar os casos que morrem são diferentes e menores dos que as de identificar os casos que sobrevivem.

Em menores de um ano de idade, houve poucos casos de meningite por Hib até os três meses de vida, provavelmente por causa da aquisição de anticorpos pela placenta e pelo leite humano (amamentação), que conferem proteção até essa idade. Coerentemente, houve aumento do número de casos dos cinco aos nove meses de vida, idade em que a imunidade passiva termina e a criança ainda não possui mecanismos de defesa imunológica completamente formados.

No Estado de Minas Gerais, no período de 1993 a 1997, 49,0\% das meningites notificadas foram bacterianas e $6,0 \%$ foram causadas por Hib. A meningite por Hib foi responsável por $12,7 \%$ dos casos de meningites bacterianas notificados, enquanto no Estado de São Paulo essa proporção foi de 8,5\% (Foccacia \& Oselka, 1996). Em Minas Gerais, das meningites bacterianas especificadas, $20,0 \%$ foram por Hib e $37,0 \%$ destas meningites ocorreram em menores de um ano de idade. Esse resultado reforça a importância da vacina como medida de saúde pública, pois a incidência e a letalidade da doença no Estado é relevante. Considera-se, também, que pode estar subestimada, por ser 
proveniente de dados de notificações cujas limitações são conhecidas.

Embora não permitam estimativas precisas, as bases do método podem ser definidas: o quadro atual sugere subestimativa da ocorrência de meningite por Hib, já que os diagnósticos falso-positivos parecem menos prováveis do que os não diagnosticados, em razão da não aplicação oportuna de métodos adequados de diagnóstico, ou não informação dos diagnosticados. O uso da proporção de meningites bacterianas especificadas para estimar a proporção de meningites não especificadas é uma aproximação conveniente e intuitiva que, se não é sustentada, também não é negada por dados empíricos.

A ampliação do elenco de vacinas disponíveis para as meningites reforça a urgência em melhorar o diagnóstico etiológico. Isso é essencial para o manuseio clínico dos casos e alteração do prognóstico de uma doença de gravidade considerável. Aproximadamente 636 mil crianças entre 2 e 24 meses deverão receber doses de vacina contra o Hib, em Minas Gerais, no período de um ano. Os resultados dessa ação poderão evitar cerca de 130 casos, 25 mortes e um número substancial de seqüelas por meningites a cada ano. As implicações econômi- cas da redução de óbitos, seqüelas e internações hospitalares também são consideráveis. Esses dados fortalecem a decisão de incorporar a vacina ao PNI e reforçam a necessidade de ajustes no sistema de vigilância epidemiológica, pois, além da vacina contra o Hib, outras vacinas dispendiosas serão candidatas a compor o calendário de vacinação no futuro.

\section{Conclusões}

Os dados epidemiológicos encontrados, inclusive as estimativas, reforçam a relevância do programa de vacinação contra o Hib, já que, nos países onde foi incorporada como rotina, determinou queda acentuada na incidência das meningites e nas taxas de colonização, favorecendo inclusive as crianças não vacinadas.

Em virtude de falhas existentes no Sistema de Notificação de Doenças Transmissíveis, e devido à inserção da vacina contra Hib na vacinação de rotina do PNI, tornam-se necessários ajustes nos métodos utilizados pela vigilância epidemiológica, que permitam um acompanhamento das ações de vacinação e avaliação do impacto da vacina para a saúde pública em Minas Gerais. 


\section{Referências}

BATTAGLIN, C. R.; MALUF, E. M. C. P.; REIMANN, J. M.; MUTTA, T.; CRUZ, R. R. \& SATO, R. M. Y., 1998. Avaliação de 1 ano de implantação da vacina contra meningite por Haemophilus influenzae $\mathrm{b}$ (Hib) no calendário de imunização de rotina no Município de Curitiba, Paraná. In: EPIRIO - 98. IV Congresso Brasileiro de Epidemiologia, Anais, p. 495, Rio de Janeiro: ABRASCO.

BOUSKELA, M. A. L., 1995. Revisão sobre os Aspectos Epidemiológicos do Haemophilus influenzae Tipo $B$. Dissertação de Mestrado, Rio de Janeiro: Faculdade de Medicina, Universidade de São Paulo.

CDC (Centers for Disease Control and Prevention), 1998. Progress toward eliminating Haemophilus influenzae type b disease among infants and children-United States, 1987 - 1997. MMWR, 47:993998.

FUNKHOUSER, A.; STEINHOFF, M. C. \& WARD, J., 1991. Haemophilus influenzae disease and immunization in developing countries. Reviews of Infectious Disease, 13:S542-554.

HUSSEY, G. D.; LASSER, M. L. \& REEKIE, W. D., 1995. The costs and benefits of a vaccination programme for Haemophilus influenzae type b disease. South African Medical Journal, 85:20-25.

LEVINE, O. S.; SCHWARTZ, B.; PIERCE, N. \& KANE, M., 1998. Development, evaluation and implementation of Haemophilus influenzae type b vaccines for young children in developing countries: Current status and priority actions. Pediatric Infectious Disease Journal, 17:95-113.

MAKELA, P. H.; TAKALA, A. K.; PELTOLA, H. \& ESKOLA, J., 1992. Epidemiology of invasive Haemophilus influenzae type $\mathrm{b}$ disease. Journal of Infectious Disease, 165(Sup. 1):S2-6.

MIRANZI, S. S. C., 2000. Situação Epidemiológica das Meningites e Pneumonias Causadas por Haemophilus influenzae Tipo B, no Estado de Minas Gerais, no Período de 1993 a 1997. Dissertação de Mestrado, Rio de Janeiro: Escola Nacional de Saúde Pública, Fundação Oswaldo Cruz.
MS (Ministério da Saúde), 1999. Informe Técnico para a Implantação da Vacina contra o Haemophilus influenzae Tipo B. Brasília: Centro Nacional de Epidemiologia.

MULHOLLAND, K.; HILTON, S.; ADEGBOLA, R.; USEN, S.; OPARAUGO, A.; OMOSIGHO, C.; WEBER, M.; PALMER, A.; SCHNEIDER, G.; JOBE, K.; LAHAI, K.; JAFFAR, S.; SECKA, S.; LIN, K.; ETHEVENAUX, C. \& GRENWOOD, B., 1997. Randomised trial of Haemophilus influenzae type-b tetanus protein conjugate for prevention of pneumonia and meningitis in Gambian infants. Lancet, 349:1191-1197.

SALISBURY, D. M., 1998. Summary statement: The first international conference on Haemophilus influenzae type b infection in Asia. Pediatrics Infectious Disease Journal, 17:S93-95.

TAKALA, A. K. \& CLEMENTS, D. A., 1992. Socioeconomic risk factors for invasive Haemophilus influenzae Type b Disease. Journal of Infectious Diseases, 165(Sup. 1):S11-15.

WARD, J. I. \& ZANGWILL, K. M., 1999. Haemophilus influenzae vaccines. In: Vaccines (S. A. Plotkin \& W. A. Orenstein, ed.), pp. 183-221, Philadelphia: WB Saunders.

WHO (World Health Organization), 1996. Generic Protocol for Population-Based Surveillance of Haemophilus influenzae Type B. Atlanta: Centers for Disease Control and Prevention/Geneva: WHO.

WHO (World Health Oraganization), 1997. Accelerating the Control of Haemophilus influenzae Type B (Hib) Disease. Geneva: WHO.

Recebido em 26 de dezembro de 2001

Versão final reapresentada em 25 de novembro de 2002 Aprovado em 9 de abril de 2003 